\title{
Article \\ Study of Resistance to Helium Swelling of Lithium-Containing Ceramics under High-Temperature Irradiation
}

\author{
Dmitriy I. Shlimas ${ }^{1,2}$, Artem L. Kozlovskiy ${ }^{1,3, * \mathbb{D}}$, Askar Kh. Syzdykov ${ }^{3}$, Daryn B. Borgekov ${ }^{1,2}$ \\ and Maxim V. Zdorovets $1,2,4$ (D) \\ 1 Laboratory of Solid State Physics, The Institute of Nuclear Physics, Almaty 050032, Kazakhstan; \\ shlimas@mail.ru (D.I.S.); borgekov@mail.ru (D.B.B.); mzdorovets@inp.kz (M.V.Z.) \\ 2 Engineering Profile Laboratory, L.N. Gumilyov Eurasian National University, Nur-Sultan 010008, Kazakhstan \\ 3 Institute of Geology and Oil and Gas Business, Satbayev University, Almaty 050032, Kazakhstan; \\ a.syzdykov@satbayev.university \\ 4 Department of Intelligent Information Technologies, Ural Federal University, 620075 Yekaterinburg, Russia \\ * Correspondence: kozlovskiy.a@inp.kz; Tel./Fax: +77-024-413-368
}

Citation: Shlimas, D.I.; Kozlovskiy, A.L.; Syzdykov, A.K.; Borgekov, D.B.; Zdorovets, M.V. Study of Resistance to Helium Swelling of LithiumContaining Ceramics under HighTemperature Irradiation. Crystals 2021, 11, 1350. https://doi.org/ $10.3390 /$ cryst 11111350

Academic Editor: Anton Meden

Received: 14 October 2021

Accepted: 3 November 2021

Published: 7 November 2021

Publisher's Note: MDPI stays neutral with regard to jurisdictional claims in published maps and institutional affiliations.

Copyright: (c) 2021 by the authors. Licensee MDPI, Basel, Switzerland. This article is an open access article distributed under the terms and conditions of the Creative Commons Attribution (CC BY) license (https:/ / creativecommons.org/licenses/by/ $4.0 /)$.

\begin{abstract}
The aim of this work was to study resistance to helium accumulation processes in the structure of the surface layer of lithium-containing ceramics and the subsequent destruction and embrittlement processes, depending on radiation fluence. The objects of study were $\mathrm{Li}_{2} \mathrm{TiO}_{3}$-type ceramics obtained by thermal sintering. The fluence dependency of changes in the structural and strength properties of ceramics was determined to be in the range from $10^{18}$ to $10^{22} \mathrm{ion} / \mathrm{m}^{2}$, which corresponded to the concentration of implanted helium from $0.01 \%$ to $0.8-1$ at. $\%$. Irradiation was carried out at a temperature of $700{ }^{\circ} \mathrm{C}$, which made it possible to simulate the processes of radiation damage that were closest to the real conditions in the reactor core. During the studies carried out, it was found that, at irradiation fluences of $10^{18}-10^{20} \mathrm{ion} / \mathrm{m}^{2}$, the formation of point radiation defects was equaled by the process of thermal annealing of defects, as a result of which the concentration of defects and their effect on the change in the structural and strength properties of ceramics were insignificant. An increase in the concentration of implanted helium in the structure of the surface layer to above 0.5 at.\% led to the dominance of radiation damage processes over the annealing of defects and the formation of gas-filled cavities, which negatively affects the strength of ceramics.
\end{abstract}

Keywords: lithium-containing ceramics; helium swelling; embrittlement; implantation; radiation exposure

\section{Introduction}

As is known, the use of new types of materials in the design of thermonuclear reactors requires special attention to such parameters as resistance to temperature extremes, highdose radiation load, mechanical strength, etc. [1-3]. Lithium-containing ceramics are one of the promising materials for thermonuclear power engineering, in particular, for the production and further production of tritium $[4,5]$. This class of ceramics, used as blanket materials in most cases, has high resistance to chemical corrosion and mechanical stress, as well as good thermal conductivity and heat capacity. The presence of lithium in the structure of ceramics makes it possible to accumulate tritium as a result of nuclear reactions of the ${ }^{6} \mathrm{Li}+\mathrm{n} \rightarrow{ }^{4} \mathrm{He}+\mathrm{T}+4.8 \mathrm{MeV}$ type. At the same time, the high rate of tritium release from ceramics based on lithium titanates, as well as resistance to high temperatures, has made them one of the promising materials for next-generation reactors and thermonuclear installations [6-8].

However, the classical reaction of tritium formation under the action of thermal neutrons is accompanied by the formation of helium, the accumulation of which can lead to negative consequences associated with its poor solubility and high mobility. At the same time, the formation of gas-filled bubbles, due to the agglomeration of helium near the surface layer, can lead to embrittlement and swelling of the near-surface layer, which not 
only affects the mechanical and strength properties of ceramics, but can also create additional obstacles to the tritium release $[9,10]$. As a rule, the formation of gas-filled bubbles under real operating conditions takes a rather long time, and the transmutation processes arising during neutron irradiation do not always allow working with these samples and fully studying all structural changes in the samples [11]. At the same time, the choice of types of lithium-containing ceramics for the production of tritium requires knowledge of the kinetics of radiation damage as a result of the accumulation of helium in the structure and its further evolution. To solve this problem, model experiments are increasingly used in heavy ion accelerators, which make it possible to irradiate ceramic samples with large fluences of helium ions, comparable to the results of nuclear reactions in the production of tritium $[9,10]$. At the same time, an important issue is the competition between the two processes occurring simultaneously in the material exposed to irradiation in the reactor core. These processes are the thermal annealing of defects, including those formed as a result of radiation damage, which occurs when exposed to elevated temperatures, and the formation of point defects under the action of irradiation and the subsequent formation of gas-filled bubbles [12-14].

The aim of this work was to study the resistance to the helium accumulation processes in the structure of the surface layer of lithium-containing ceramics and subsequent processes of destruction and embrittlement, depending on the radiation fluence. Lithiumcontaining ceramics of the $\mathrm{Li}_{2} \mathrm{TiO}_{3}$ type were chosen owing to the wide potential of their application as blanket materials for thermonuclear reactors and reactors of a new generation. Interest in the study of the helium-swelling processes in lithium-containing ceramics, including during irradiation at elevated temperatures, arises from the possibility of obtaining data on the kinetics of radiation damage during the formation of gas-filled inclusions, as well as the study of the competition between the processes of thermal annealing of defects and the formation of point defects as a result of radiation damage [15-17].

\section{Experimental Section}

$\mathrm{Li}_{2} \mathrm{TiO}_{3}$ ceramics obtained using a solid-phase synthesis method by mixing the components $\mathrm{TiO}_{2}$ and $\mathrm{LiClO}_{4} \cdot 3 \mathrm{H}_{2} \mathrm{O}$ in equal stoichiometric proportions were chosen as the study samples. After weighing, the resulting mixture was placed in a tungsten carbide glass for a planetary mill, in a volume of $1 / 3$ of the total volume of the glass, and ground for $1 \mathrm{~h}$ at a speed of $500 \mathrm{rpm}$. These grinding conditions made it possible to obtain a mixture that was homogeneous in composition and size, but that the temperature of the glass did not exceed $60^{\circ} \mathrm{C}$ in the process of grinding, ensuring that phase transformation processes did not occur. According to the data from the energy dispersive analysis used to control the grinding process, it was found that no traces of tungsten carbide compounds were found in the composition of the ceramics, which indicated the absence of impurities in the composition of the ceramics. After grinding, the resulting mixture was annealed in a muffle furnace in an oxygen-containing atmosphere at a temperature of $1100{ }^{\circ} \mathrm{C}$ for $5 \mathrm{~h}$, followed by cooling together with the furnace for $24 \mathrm{~h}$. These annealing conditions were necessary for the formation of a stable $\mathrm{Li}_{2} \mathrm{TiO}_{3}$ phase, which is formed at temperatures above $1000{ }^{\circ} \mathrm{C}$ according to earlier studies [18]. To study the radiation resistance, the obtained powders were pressed into tablets with a diameter of $5 \mathrm{~mm}$ and a thickness of $0.5 \mathrm{~mm}$.

Simulation of the processes of helium swelling of the near-surface layer was carried out by irradiation with $\mathrm{He}^{2+}$ ions with an energy of $40 \mathrm{keV}$ and fluencies of $10^{18}-10^{22} \mathrm{ion} / \mathrm{m}^{2}$. A series of experiments on irradiation was carried out in a DC-60 heavy ion accelerator (NurSultan, Kazakhstan). Irradiation was carried out at a temperature of $700{ }^{\circ} \mathrm{C}$, which made it possible to simulate the processes of radiation damage that are closest to real conditions in the reactor core. A ceramic holder was used as a heater, allowing the samples to be heated during irradiation in the temperature range from 100 to $700{ }^{\circ} \mathrm{C}$. The experiments on high-temperature irradiation were carried out in the following sequence. The ceramic sample was placed in a special holder and placed in the irradiation chamber. Then, the holder from the samples was heated to the required temperature of $700^{\circ} \mathrm{C}$ and stabilized 
for $1 \mathrm{~h}$, after which it was irradiated to a predetermined fluence. The control over the fluence was achieved using Faraday cylinders; the error in the fluence was set to no more than $1-2 \%$. After irradiation, the sample was cooled to room temperature in an irradiation chamber in a vacuum, in order to avoid oxidation and destruction processes as a result of a sharp temperature drop and interactions with the atmosphere.

Analysis of the phase composition, as well as changes in structural parameters and kinetics of swelling and degradation as a result of irradiation and subsequent radiation damage, was carried out using the method of X-ray phase analysis. The implementation of this method was carried out using an X-ray diffractometer D8 Advance ECO (Bruker, Germany) in the geometry of the Bragg-Brentano survey $\left(2 \theta^{\circ}\right)$ in the angular range $2 \theta=25-75^{\circ}$, with a step of $0.03^{\circ}$ and an acquisition time of $1 \mathrm{~s}$ at a point. A copper tube with a wavelength $\mathrm{Cu}-\mathrm{k} \alpha=1.5406 \AA$, X-ray generator parameter: voltage $=40 \mathrm{kV}$, current $25 \mathrm{~mA}$, was used as the X-ray source. The phase composition as well as the parameters of the crystal lattice were determined by comparing the experimental diffraction patterns with the card values from the PDF-2(2016) database in the DiffracEVA v.4.2 program code based on the full-profile method of analysis.

The density of ceramics was calculated based on changes in structural parameters using Equation (1):

$$
p=\frac{1.6602 \sum A Z}{V},
$$

where $V_{0}$ is the unit cell volume, $Z$ is the number of atoms in the crystal cell, and $A$ is the atomic weight of atoms. The integral porosity, the value of which characterizes the imperfection of the crystal structure, including the presence of hollow inclusions and regions of disordering, was calculated from Equation (2):

$$
P_{\text {dil }}=\left(1-\frac{p}{p_{0}}\right) * 100 \%,
$$

where $p_{0}$ is the density of the reference sample; in the case of irradiation, the value of the density of ceramics in the initial state was used as the value of $p_{0}$.

The study of the formation of defective regions as a result of irradiation was carried out using the method of transmission electron microscopy, implemented on a JEOL JEM1400 Plus (JEOL Ltd., Akishima, Tokyo, Japan) at an accelerating voltage of $120 \mathrm{kV}$.

The study to determine the strength properties was carried out by performing tests for a single compression of the samples in a press with a compression speed of $0.1 \mathrm{~mm} / \mathrm{min}$. The tests were carried out on a series of 5 samples exposed to irradiation with subsequent determination of the measurement error and standard deviation. The limit characterizing the stability was the pressure that the sample withstands before the beginning of the cracking stage. The degree of decrease in resistance to cracking was determined by determining the pressure difference at which cracking of the samples began in the initial and irradiated state.

The determination of hardness was carried out using the indentation technique, implemented using a microhardness tester, where a Vickers pyramid was used as an indenter. The maximum load on the indenter was $10 \mathrm{~N}$ and the pressing time was $15 \mathrm{~s}$. The softening degree of ceramics was determined from the difference in hardness values in the initial and irradiated samples.

\section{Results and Discussion}

Figure 1 shows the results of modeling the values of the concentration of implanted helium (at.\%) and atomic displacements depending on the irradiation fluence. The simulation was carried out based on the results of the SRIM Pro 2013 program code [19], as well as the formulas proposed by in the work of G.W. Egeland et al., which allow the assessment of the degree of radiation damage caused by low-energy ions [20]. During the simulation, the standard Kinchin-Pease model was used and the material density $\left(3.53 \mathrm{~g} / \mathrm{cm}^{3}\right)$ was chosen taking into account the $\mathrm{X}$-ray analysis data obtained from experimental samples. 


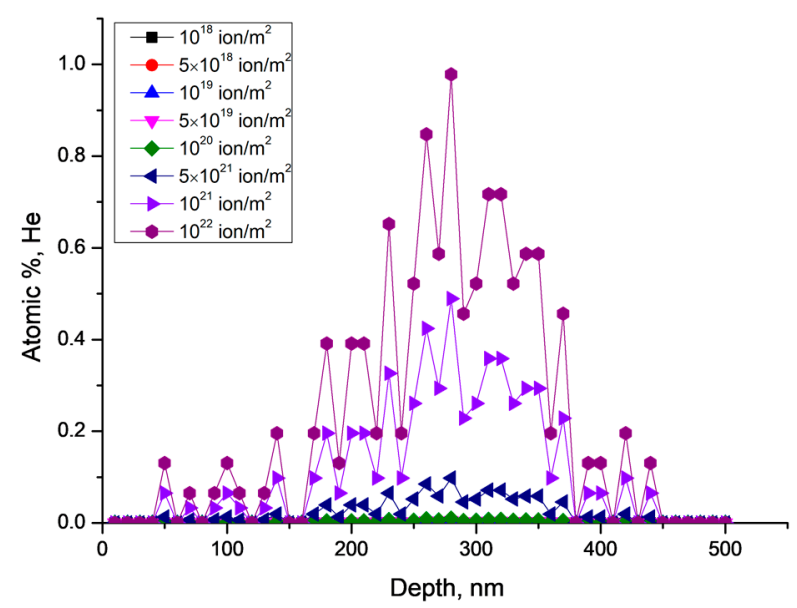

(a)

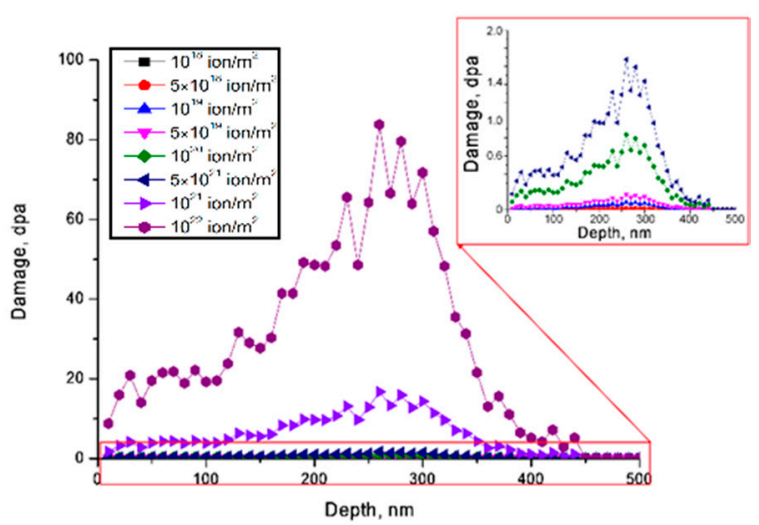

(b)

Figure 1. Simulation results in SRIM Pro 2013: (a) depth profile of $\mathrm{He}^{2+}$ ion implantation as a result of irradiation; (b) displacements per atom (dpa) versus the depth (for different fluences).

As can be seen from the data presented in Figure 1b, an increase in the irradiation fluence leads to an increase in the dpa value. At the same time, the value of the displacements at a depth of 250-270 nm, corresponding to the maximum path length of ions in the ceramic, was 10-15 dpa for a fluence of $5 \times 10^{21} \mathrm{ion} / \mathrm{m}^{2}$ and $70-85 \mathrm{dpa}$ for a fluence of $1 \times 10^{22} \mathrm{ion} / \mathrm{m}^{2}$. The concentration of implanted helium, in turn, for these irradiation fluences, was $0.4-0.5$ and $0.8-1.0$ at.\%. for fluences of $5 \times 10^{21} \mathrm{ion} / \mathrm{m}^{2}$ and $1 \times 10^{22}$ ion $/ \mathrm{m}^{2}$, respectively.

Figure 2 shows the results of X-ray phase analysis of the studied ceramics depending on the radiation fluence. Using a full-profile analysis of the position and shape of the lines, as well as comparing their positions with the PDF-2 database, it was found that the closest phase with a probability of $93 \%$ was the monoclinic phase of $\mathrm{Li}_{2} \mathrm{TiO}_{3}$ with the spatial symmetry $C 2 / c(15)$ and the crystal lattice parameters $a=4.9913 \AA, b=8.6811 \AA, c=9.6617 \AA$, $\beta=99.96^{\circ}$ (PDF-01-077-8280). In fact, the application of the method of mechanochemical synthesis led to significant deviations from the intensities of the reference values, while the refinement of the parameters used in the DiffracEVA v.4.2 program code (Bruker, Germany) allowed us to determine the coincidence of the experimentally obtained diffractogram with the card values, taking into account the recalculation of intensities and the position of diffraction lines. The absence of some of the reflections and the discrepancy between the intensity values of the experimental sample and the reference sample may be due to the synthesis processes, leading to the reorientation and the appearance of the selected textures.

The general overview of the diffraction patterns of the samples under study before and after irradiation indicated that the main structural changes resulting from irradiation were associated with deformation processes and the appearance of regions of disordering. In this case, the appearance of new diffraction reflections characteristic of the processes of phase formation or phase transformations was not observed. Changes in X-ray reflections characteristic of deformation processes were associated with a shift of the peaks to the region of small angles, which indicated a distortion of interplanar spacings and swelling of the crystal lattice (see Figure $2 b$ ).

Deformation processes are primarily associated with energy losses of incident ions and the subsequent implantation of helium into the structure of the surface layer, as well as its agglomeration into larger clusters or bubbles. At the same time, an increase in the irradiation fluence leads to large deformations of the structure and a shift in reflections, which indicates a cumulative effect. According to the X-ray diffraction data, at irradiation fluences of $10^{18}-5 \times 10^{19} \mathrm{ion} / \mathrm{m}^{2}$, no displacements of reflections were observed, which indicated that almost all formed point defects were annihilated owing to the high temperature of the sample as a result of heating. At the same time, the resulting structural defects 
in the sample at low concentrations of implanted helium 0.01-0.1 at.\%, in most cases, annihilate, without the possibility of forming cluster defects. An increase in the irradiation fluence and, consequently, the concentration of implanted helium, leads to the formation of agglomerates in the structure consisting of helium, which, owing to its high mobility and low solubility, is able to move through the structure and occupy cavities in the lattice. In this case, for fluences above $5 \times 10^{19} \mathrm{ion} / \mathrm{m}^{2}$, the main deformation processes were associated with a shift in reflections and distortion of their shape, a change that indicates the appearance of additional stresses in the structure caused by irradiation. In view of the low energy of ions, the contributions from energy losses during elastic and inelastic collisions of ions were of the same order of magnitude, which indicates their equally probable effect on structural changes. As a result of such collisions, a large amount of kinetic energy is transferred to the crystal structure, which can lead to both the displacement of atoms and the appearance of locally heated regions. At the same time, in the case of high-temperature irradiation, when the amplitude of thermal vibrations of atoms in the lattice is increased by external heating, any external influence can lead to both the displacement of atoms and the appearance of relaxation processes of annealing of defects. However, the processes of annihilation of the resulting defects as a result of irradiation occur when the displacement value is no more than 1-3 dpa. An increase in the irradiation fluence leads to an increase in implanted helium concentration, as well as an increase in atomic displacement, which leads to deformation of the crystal structure.

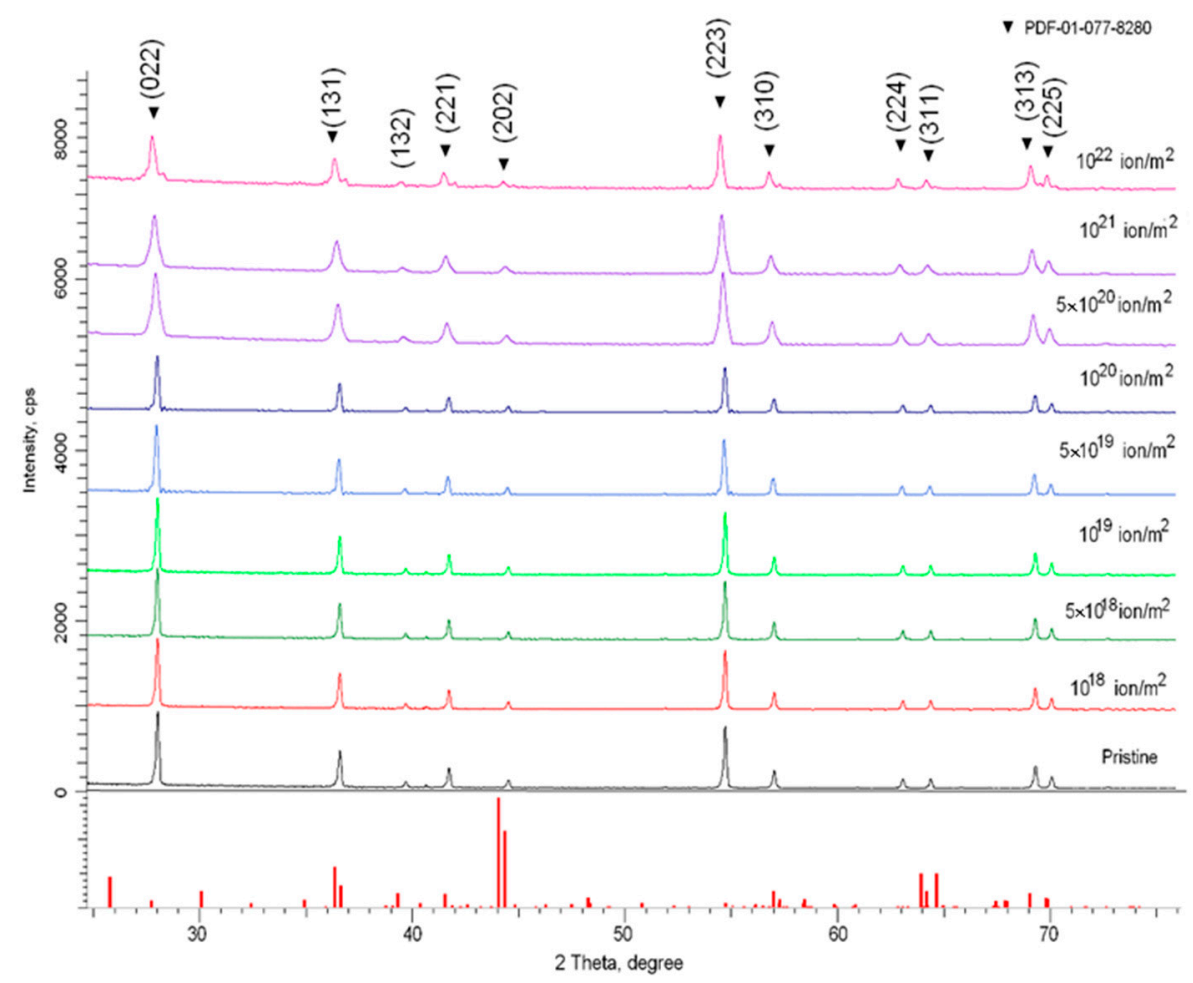

(a)

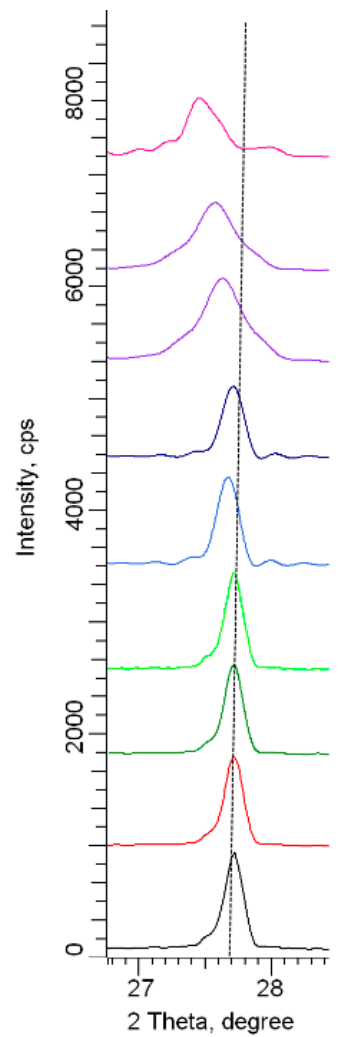

(b)

Figure 2. (a) X-ray diffraction patterns of the studied ceramics depending on the irradiation fluence; (b) dynamics of changes in the main reflex at $2 \theta=27.7^{\circ}$.

Figure 3a shows the results of assessing the change in the interplanar distances deformation degree and the content of amorphous inclusions formed as a result of irradiation. The shift value was estimated from the shift of the diffraction reflection at $2 \theta=27.7^{\circ}$. The determination of the value of the displacement of interplanar distances was carried out using the Rietveld method. The interplanar distance deformation degree was esti- 
mated by calculating the difference in the values of interplanar distances of the main diffraction reflections before and after irradiation, with subsequent normalization to $100 \%$. The content of amorphous inclusions formed as a result of irradiation was estimated by calculating the crystallinity degree of the samples before and after irradiation and then determining their difference. The crystallinity degree was determined according to the standard procedure for calculating the contributions of the areas of the main reflections and background radiation by approximating the obtained diffraction patterns with a standard set of pseudo-Voigt functions.

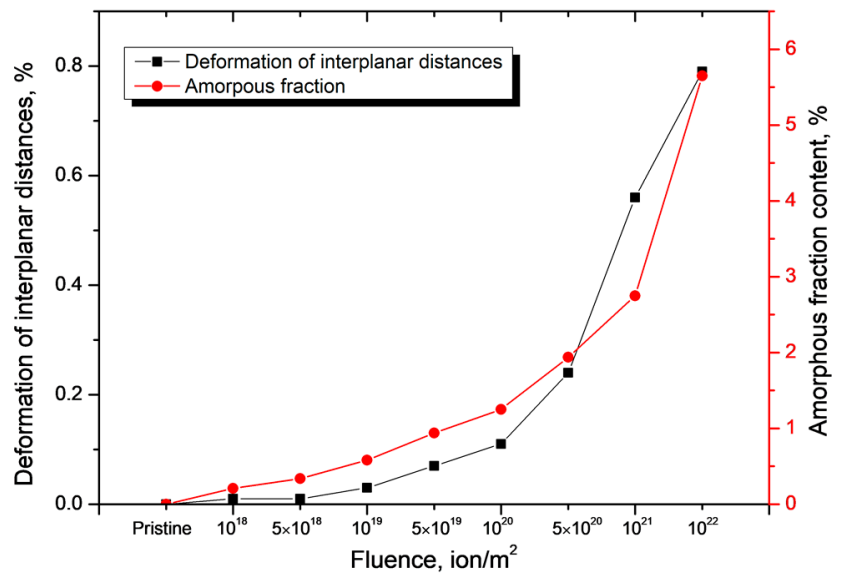

(a)

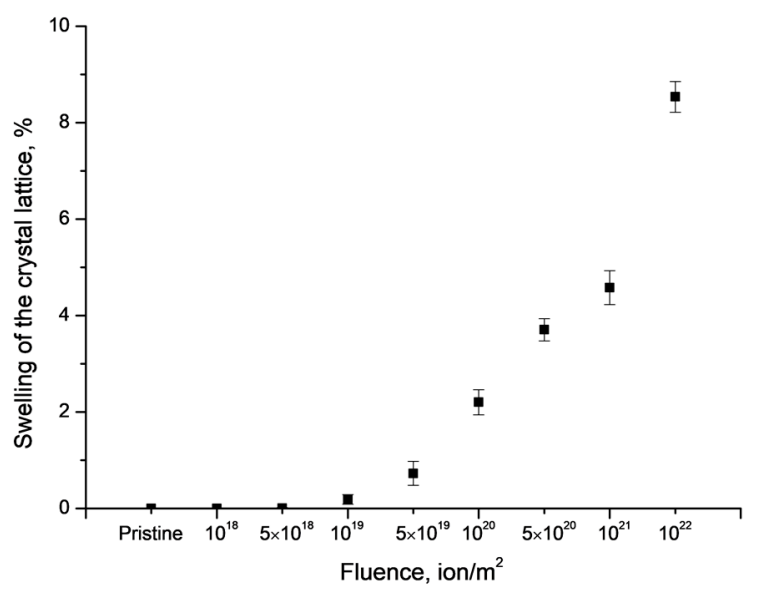

(b)

Figure 3. (a) Changes in the values of the degree of deformation of interplanar distances and the content of amorphous inclusions; (b) crystal lattice swelling versus irradiation fluence.

As can be seen from the data presented, the greatest changes in structural distortions and amorphization of the structure were observed at irradiation fluences above $10^{20}$ ion $/ \mathrm{m}^{2}$, which were characterized by a sharp increase in the implanted helium concentration, as well as in the magnitude of atomic displacements. An increase in the irradiation fluence, leading to an increase in atomic displacements, leads to deformation and swelling of the ceramics. At the same time, the formation of amorphous inclusions and an increase in their contribution to the structure may be due to the processes of ballistic melting and cascade collisions, which lead to the formation of amorphous inclusions in the structure. The formation of amorphous inclusions was most clearly seen when analyzing the shape of diffraction peaks in the case of irradiation with fluences above $10^{20} \mathrm{ion} / \mathrm{m}^{2}$. For these samples, when analyzing the diffraction patterns, it can be seen that not only a shift of the peaks occurs, but also a change in their shape with the formation of asymmetry in the region of small angles, which indicates the processes of amorphization of the structure as a result of irradiation. At the same time, the results of changes in the volume of the crystal lattice, which characterize the swelling processes, also indicated the amorphization and deformation of the structure of ceramics (see Figure $3 b$ ). As can be seen from the presented results, swelling, as well as the processes of deformation and amorphization, were most intensely manifested at fluences above $10^{20}$ ion $/ \mathrm{m}^{2}$, which indicated the resistance of ceramics to irradiation with lower fluences.

Figure 4 shows the results of TEM images of the studied samples of ceramics in the initial and irradiated state, which reflect the formation of defect regions as a result of irradiation and the formation of amorphous inclusions. As can be seen from the presented data, at an irradiation fluence of $10^{20} \mathrm{ion} / \mathrm{m}^{2}$, the formation of long-shaped defect inclusions was observed in the grain structure. An increase in the irradiation fluence to $5 \times 10^{21} \mathrm{ion} / \mathrm{m}^{2}$ or higher led to the formation of spherical or sphere-like inclusions in the grain structure, the size of which increased with increasing fluence. The formation of such inclusions indicated 
a partial amorphization of the structure as a result of the accumulation of defects, as well as the agglomeration of helium in the grains.

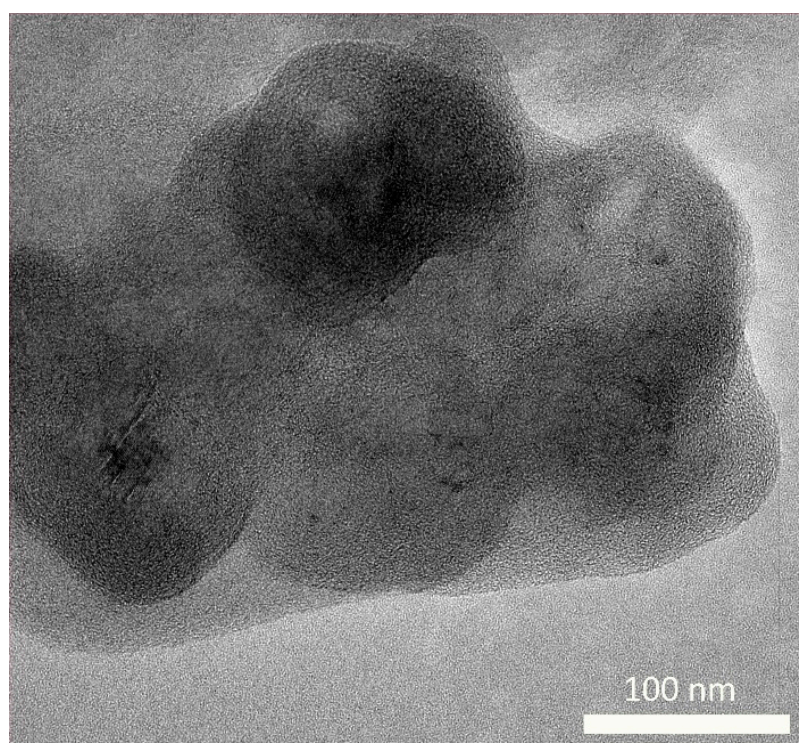

(a)

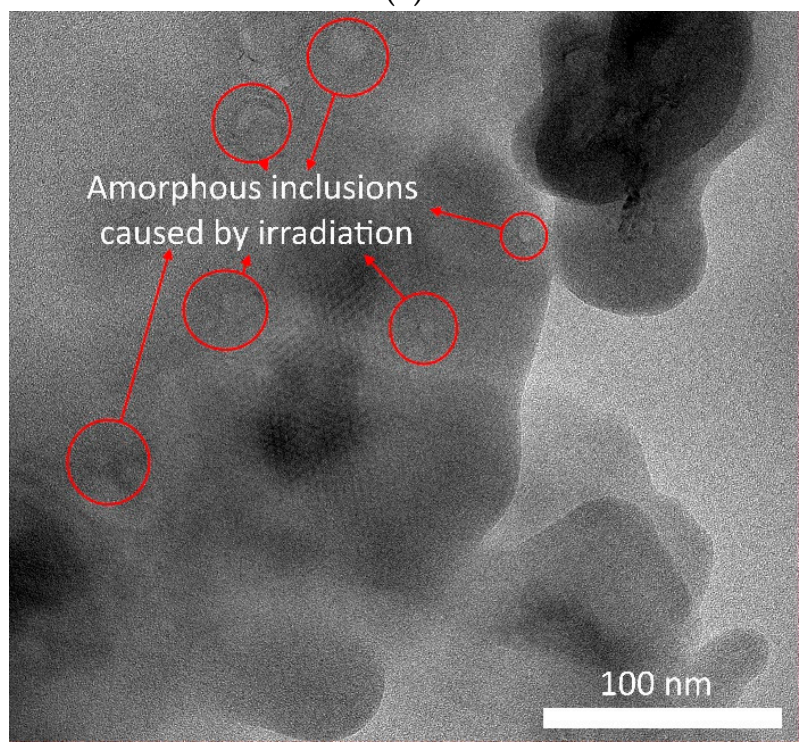

(c)

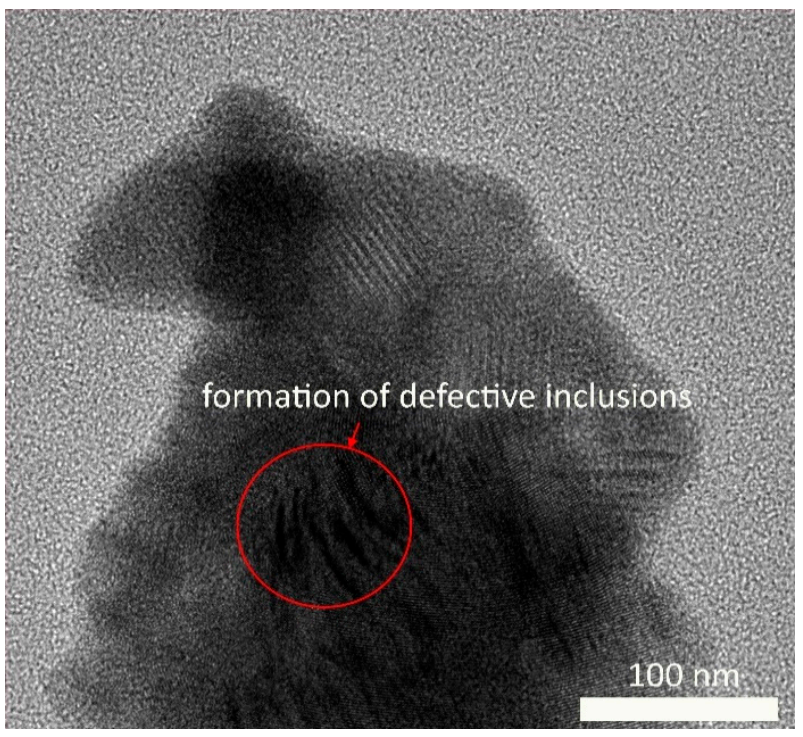

(b)

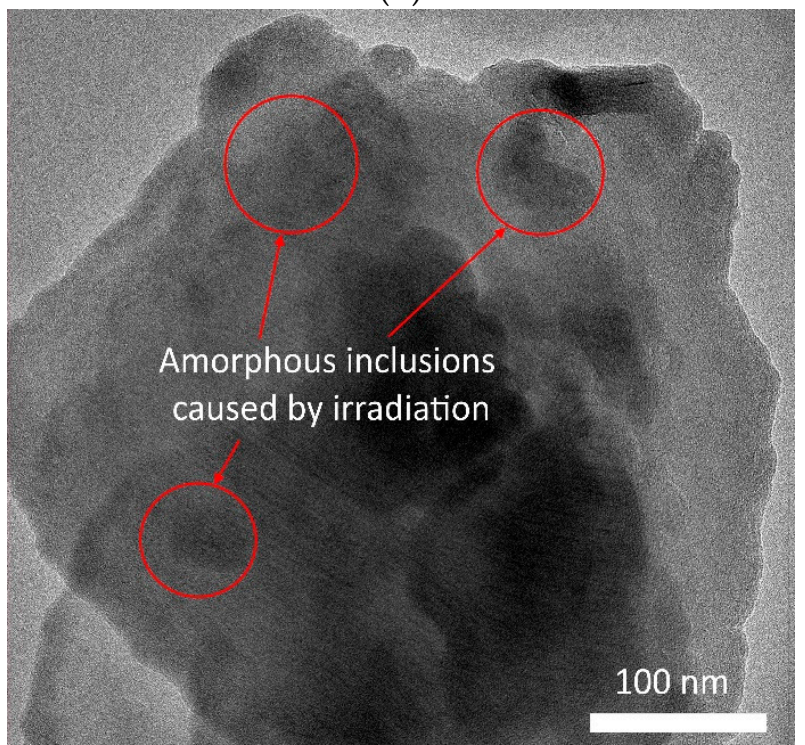

(d)

Figure 4. TEM images of the studied ceramics before and after irradiation: (a) pristine sample; (b) $10^{20}$ ion $/ \mathrm{m}^{2}$; (c) $5 \times 10^{21}$ ion $/ \mathrm{m}^{2} ;$ (d) $10^{22}$ ion $/ \mathrm{m}^{2}$.

Figure 5 shows the results of changes in the density and porosity of ceramics depending on the irradiation fluence. The density was calculated based on the results of changes in the volume of the crystal lattice. As can be seen from the presented data, the resistance to the formation of porous inclusions, due to the change in density as a result of irradiation, was retained for irradiation fluences of $10^{18}-5 \times 10^{19}$ ion $/ \mathrm{m}^{2}$. The absence of significant changes in density and porosity indicated that the formed point defects as a result of irradiation at these fluences were partially annealed and did not form a high concentration of distortions and deformations in the structure. An increase in the irradiation fluence, which led to an increase in the concentration of implanted helium and the magnitude of atomic displacements, led to the formation of amorphous inclusions and a decrease in the density of ceramics; in the future, this may negatively affect the strength properties. 


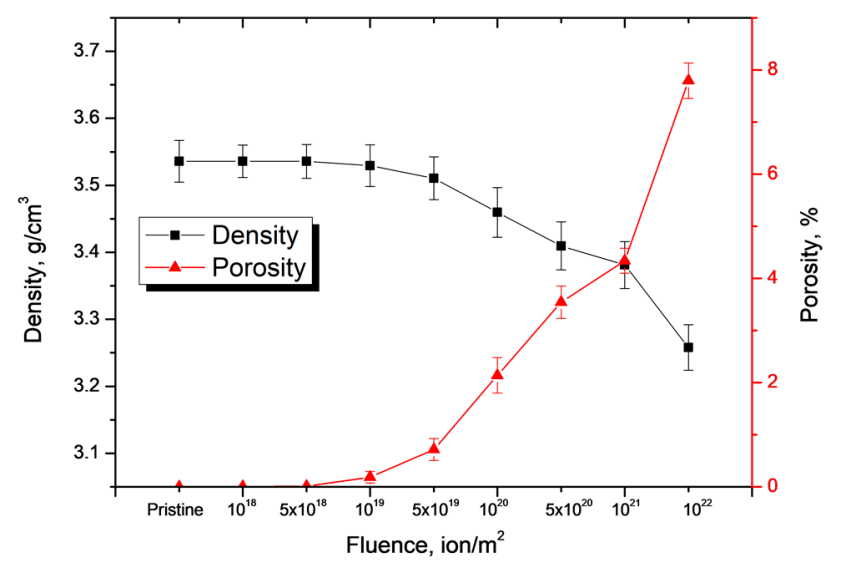

Figure 5. Change in the density and porosity of ceramics depending on the irradiation fluence.

Figure 6a shows the results of studies of strength characteristics, in particular, the determination of resistance to cracking under external load by a single compression. As can be seen from the obtained dependences, the synthesized ceramics had a sufficiently high resistance to cracking and degradation of strength properties as a result of irradiation with fluences of $10^{18}-10^{20}$ ions $/ \mathrm{m}^{2}$ for which the decrease in stability was no more than $5-7 \%$. An increase in the irradiation fluence above $10^{20} \mathrm{ion} / \mathrm{m}^{2}$ led to a sharp deterioration in the resistance to cracking and a decrease in the resistance of ceramics. This behavior was associated with the degradation of the crystal structure as a result of the accumulation of implanted helium in the structure of the surface layer and subsequent partial amorphization of the crystal structure.

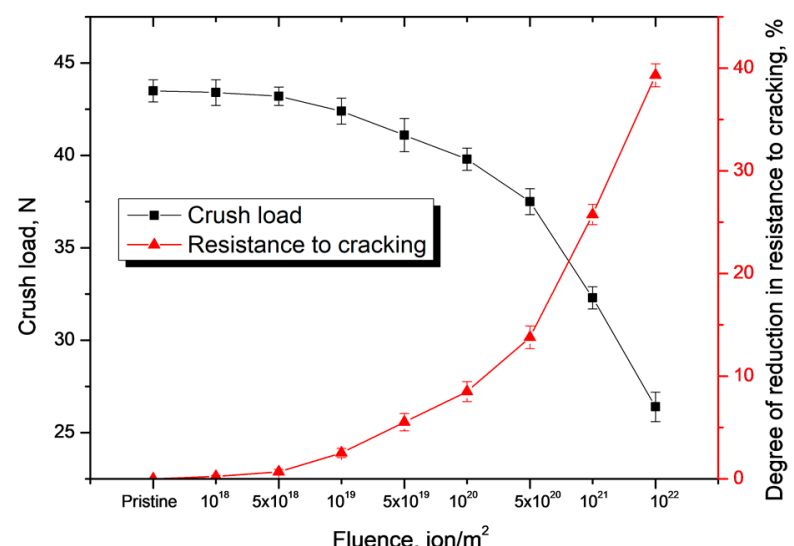

(a)

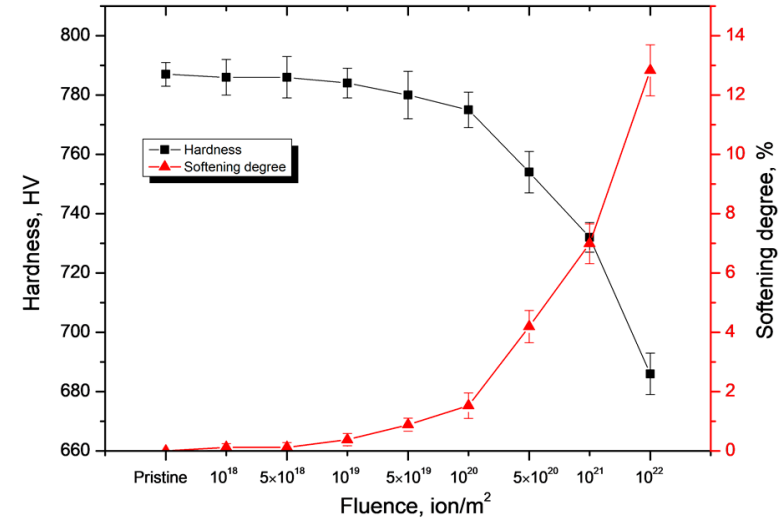

(b)

Figure 6. (a) The dependence of the change in the values of resistance to cracking of ceramics under an external load; (b) the change in hardness and softening degree of ceramics depending on the irradiation fluence.

The data on the dependences of changes in the hardness indices of the near-surface layer exposed to irradiation, presented in Figure 6b, reflect a similar trend as in the resistance to cracking. At the same time, the maximum softening degree, which was estimated from the indentation geometry, was more than $12 \%$ at the maximum irradiation fluence.

\section{Conclusions}

In the course of the study, it was found that, at irradiation fluences of $10^{18}-10^{20} \mathrm{ion} / \mathrm{m}^{2}$, the formation of point radiation defects was equaled by the process of thermal annealing of defects, as a result of which the concentration of defects and their effect on the change in the structural and strength properties of ceramics is insignificant. An increase in the concentration of implanted helium in the structure of the surface layer to above 0.5 at. $\%$ 
led to the dominance of radiation damage processes over the annealing of defects and the formation of gas-filled cavities, which negatively affected the strength of the ceramics.

It can be concluded that the synthesized $\mathrm{Li}_{2} \mathrm{TiO}_{3}$ ceramics have a sufficiently high degree of resistance to degradation and swelling as a result of irradiation with helium ions, up to fluences of $10^{20} \mathrm{ion} / \mathrm{m}^{2}$. At high irradiation fluences, helium bubbles and amorphous inclusions begin to form in the structure, which leads to a deterioration in the structural properties, as well as a decrease in the strength and resistance to cracking of ceramics.

It is known that, as a result of nuclear reactions under the action of neutrons in a ceramic material, helium accumulates in the structure, the concentration of which strongly depends on the fuel production degree, lithium burnout, and service life. At the same time, the critical doses for the accumulation of defects in the structure are considered to be values of more than $50 \mathrm{dpa}$ (at a flux of $\sim 10^{13-14}$ unit $/ \mathrm{cm}^{2} * \mathrm{~s}$ ), which are characterized by serious violations of the integrity of the structure. In our case, the maximum irradiation fluence, according to calculations, led to a displacement of more than $70 \mathrm{dpa}$ (at a flux of $\sim 10^{12-13}$ unit $/ \mathrm{cm}^{2} * \mathrm{~s}$ ), which corresponded to an implanted helium concentration of no more than 1.0 at.\%. At the same time, in reactor tests with neutron fluxes, it is rather difficult to determine the concentration of accumulated helium, owing to the complexity of detecting and capturing helium. In most cases, the concentration of helium is determined indirectly by the results of microscopy, reflecting the formation of helium bubbles and deformation of the structure. It is also worth noting that today there are few experimental data for these types of ceramics, reflecting the dynamics of structural changes as a result of the accumulation of helium in the material. In this context, obtaining data on the effect of helium on the kinetics of structural and strength changes, in particular, at high irradiation fluences, is not only of scientific interest but also of practical interest for using data in the design of new generation reactors, including thermonuclear reactors.

Author Contributions: Conceptualization, M.V.Z., D.I.S., D.B.B. and A.L.K.; methodology, D.B.B., D.I.S. and A.L.K.; formal analysis, M.V.Z.; investigation, D.I.S., A.K.S., A.L.K. and M.V.Z.; resources, M.V.Z.; writing—original draft preparation, review and editing, D.I.S., M.V.Z., D.B.B. and A.L.K.; visualization, M.V.Z.; supervision, M.V.Z. All authors have read and agreed to the published version of the manuscript.

Funding: This research was funded by the Science Committee of the Ministry of Education and Science of the Republic of Kazakhstan (No. AP08855734).

Conflicts of Interest: The authors declare that they have no conflict of interest.

\section{References}

1. Van der Laan, J.G.; Fedorov, A.V.; van Til, S.; Reimann, J. Ceramic breeder materials. Compr. Nucl. Mater. 2012,4 , 463-510.

2. Chen, Z.; Lu, W.; Wang, J.; Zhang, S.; Chu, D.; Wang, W.; Pu, W. Lithium/titanium ratio: A key factor on crystal structure and mechanical properties of lithium titanate pebbles for tritium breeder. J. Nucl. Mater. 2021, 553, 153033. [CrossRef]

3. Ying, A.; Reimann, J.; Boccaccini, L.; Enoeda, M.; Kamlah, M.; Knitter, R.; Gan, Y.; van der Laan, J.G.; Magielsen, L.; DI Maio, P.A.; et al. Status of ceramic breeder pebble bed thermo-mechanics R\&D and impact on breeder material mechanical strength. Fusion Eng. Des. 2012, 87, 1130-1137.

4. Mandal, D.; Ghuge, N.S.; Jadeja, M.C. Development and demonstration of a semi-automatic system for the bulk production of lithium titanate $\left(\mathrm{Li}_{2} \mathrm{TiO}_{3}\right)$ pebbles by solid state reaction process (SSRP). Fusion Eng. Des. 2020, 159, 111871. [CrossRef]

5. Yang, M.; Zhao, L.; Ran, G.; Gong, Y.; Wang, H.; Peng, S.; Xiao, C.; Xiao, C.; Chen, X.; Lu, T. Tritium release behavior of Li ${ }_{2} \mathrm{TiO}_{3}$ and $2 \mathrm{Li}_{2} \mathrm{TiO}_{3}-\mathrm{Li}_{4} \mathrm{SiO}_{4}$ biphasic ceramic pebbles fabricated by microwave sintering. Fusion Eng. Des. 2021, 168, 112390. [CrossRef]

6. Liu, W.; Di, J.; Zhang, W.; Xue, L.; Yan, Y. Influence of titanium sources on the microstructures and properties of $\mathrm{Li}_{2} \mathrm{TiO}_{3}$ ceramics prepared by hydrothermal method. Fusion Eng. Des. 2018, 138, 364-371. [CrossRef]

7. Hong, M.; Zhang, Y.; Zhang, Y.; Mi, Y.; Fu, B. Characterization of $\mathrm{Li}_{2} \mathrm{TiO}_{3}$ pebbles by graphite bed process. J. Nucl. Mater. 2013, 441, 390-394. [CrossRef]

8. Kim, J.-I.; Park, Y.-H.; Ahn, M.-Y.; Kishimoto, H.; Lee, Y.; Cho, S. Effects of sintering conditions on the microstructure of $\mathrm{Li}_{2} \mathrm{TiO}_{3}$ tritium breeding materials. Fusion Eng. Des. 2020, 156, 111727. [CrossRef]

9. Gu, S.; Ji, B.; Qi, Q.; Wang, J.; Zhou, H.S.; Zhang, Y.; Luo, G.N. Effects of He irradiation on the microstructure and mechanical performance of $\mathrm{Li}_{2} \mathrm{TiO}_{3}$. Nucl. Fusion 2021, 61, 106035. [CrossRef]

10. Wang, H.; Qi, J.; Guo, H.; Chen, R.; Yang, M.; Gong, Y.; Huang, Z.; Shi, Q.; Liu, W.; Wang, H.; et al. Influence of helium ion radiation on the nano-grained $\mathrm{Li}_{2} \mathrm{TiO}_{3}$ ceramic for tritium breeding. Ceram. Int. 2021, 47, 28357-28366. [CrossRef] 
11. Tazhibayeva, I.; Beckman, I.; Shestakov, V.; Kulsartov, T.; Chikhray, Y.; Kenzhin, E.; Kiykabaeva, A.; Kawamura, H.; Tsuchiya, K. Tritium accumulation and release from $\mathrm{Li}_{2} \mathrm{TiO}_{3}$ during long-term irradiation in the WWR-K reactor. J. Nucl. Mater. 2011, 417, 748-752. [CrossRef]

12. Zinkle, S.J. Effect of irradiation spectrum on the microstructural evolution in ceramic insulators. J. Nucl. Mater. 1995, 219, 113-127. [CrossRef]

13. Nishikawa, Y.; Oyaidzu, M.; Yoshikawa, A.; Munakata, K.; Okada, M.; Nishikawa, M.; Okuno, K. Correlation between tritium release and thermal annealing of irradiation damage in neutron-irradiated $\mathrm{Li}_{2} \mathrm{SiO}_{3}$. J. Nucl. Mater. 2007, 367, 1371-1376. [CrossRef]

14. Wang, C.; Tu, H.; Su, R.; Gao, J.; King, B.V.; O'Connor, D.J.; Shi, L. Annealing effects on the structure and hardness of heliumirradiated $\mathrm{Cr}_{2} \mathrm{AlC}$ thin films. J. Am. Ceram. Soc. 2020, 104, 593-603. [CrossRef]

15. Gu, S.; Ji, B.; Qi, Q.; Wang, J.; Zhou, H.; Zhang, Y.; Luo, G.-N. The effects of irradiation and high temperature on chemical states in $\mathrm{Li}_{2} \mathrm{TiO}_{3}$. Int. J. Hydrog. Energy 2019, 44, 32151-32157. [CrossRef]

16. Shlimas, D.I.; Zdorovets, M.V.; Kozlovskiy, A.L. Synthesis and resistance to helium swelling of $\mathrm{Li}_{2} \mathrm{TiO}_{3}$ ceramics. J. Mater. Sci. Mater. Electron. 2020, 31, 12903-12912. [CrossRef]

17. Oyaidzu, M.; Morimoto, Y.; Kodama, H.; Sasaki, M.; Kimura, H.; Munakata, K.; Okuno, K. Correlation between annihilation of radiation defects and tritium release in $\mathrm{Li}_{2} \mathrm{TiO}_{3}$. J. Nucl. Mater. 2004, 329, 1313-1317. [CrossRef]

18. Shlimas, D.I.; Zdorovets, M.V.; Kozlovskiy, A.L. Formation of Stable Lithium-Containing Ceramics Using Solid-Phase Synthesis Method. Crystals 2021, 11, 1177. [CrossRef]

19. Ziegler, J.F.; Ziegler, M.D.; Biersack, J.P. SRIM-The stopping and range of ions in matter. Nucl. Instrum. Methods Phys. Res. Sect. B Beam Interact. Mater. At. 2010, 268, 1818-1823. [CrossRef]

20. Egeland, G.W.; Valdez, J.A.; Maloy, S.A.; McClellan, K.J.; Sickafus, K.E.; Bond, G.M. Heavy-ion irradiation defect accumulation in ZrN characterized by TEM, GIXRD, nanoindentation, and helium desorption. J. Nucl. Mater. 2013, 435, 77-87. [CrossRef] 